\title{
Indication for cesarean section as per Robsons's criteria- A retrospective analysis of 5000 consecutive caesarean sections
}

\author{
Anshu Baser ${ }^{1}$, Sunil Sharma ${ }^{2}$, Sushil Kumar ${ }^{2}$, Annabelle Sabu ${ }^{1}$, Akriti Gupta ${ }^{1}$, and Sadaf \\ Sheikh ${ }^{1}$ \\ ${ }^{1}$ Mahatma Gandhi Mission's Institute of Health Sciences \\ ${ }^{2}$ Mahatma Gandhi Mission's University of Health Sciences
}

September 21, 2020

\begin{abstract}
Abstract Background: The increasing incidence of cesarean section around the world is becoming a matter of concern. Many obstetricians consider it to be the easier option as opposed to vaginal delivery. However we must not forget that caesarean section is associated with increased morbidity to the patient. WHO (World Health Organization) in 2015 introduced the Robson's criteria as a standardized method to determine the rate and indications of cesarean section within a healthcare facility. We here present a retrospective analysis of 5000 cesarean sections by Robson's criteria. Material Methods: A retrospective analysis of total 5000 LSCS (lower segment cesarean section) as per Robson criteria was carried out at MGM hospital Kalamboli from 1st January 2015 to 25th December 2019. The indications for LSCS and the maternal and fetal complications were noted. Results: The overall cesarean section rate during the study period was $28 \%$. Out of the 5000 study population $32.7 \%$ comprised of group 5 (Previous Caesarean section) of Robson's classification followed by $23.04 \%$ in group 2 (labour induced or LSCS before labour starts).
\end{abstract}

\section{Hosted file}

Robson's article for BJOG.docx available at https://authorea.com/users/360594/articles/ 482226-indication-for-cesarean-section-as-per-robsons-s-criteria-a-retrospectiveanalysis-of-5000-consecutive-caesarean-sections

\section{Hosted file}

Table and figures for robson's.docx available at https://authorea.com/users/360594/articles/ 482226-indication-for-cesarean-section-as-per-robsons-s-criteria-a-retrospectiveanalysis-of-5000-consecutive-caesarean-sections 